Article

Subscriber access provided by King Abdullah University of Science and Technology Library

\title{
Dynamics, Miscibility, and Morphology in Polymer- Molecule Blends: The Impact of Chemical Functionality
}

Khanh Do, Chad Risko, John E Anthony, Aram Amassian, and Jean-Luc Bredas

Chem. Mater., Just Accepted Manuscript • DOI: 10.1021/acs.chemmater.5b02983 • Publication Date (Web): 22 Oct 2015

Downloaded from http://pubs.acs.org on October 27, 2015

\section{Just Accepted}

"Just Accepted" manuscripts have been peer-reviewed and accepted for publication. They are posted online prior to technical editing, formatting for publication and author proofing. The American Chemical Society provides "Just Accepted" as a free service to the research community to expedite the dissemination of scientific material as soon as possible after acceptance. "Just Accepted" manuscripts appear in full in PDF format accompanied by an HTML abstract. "Just Accepted" manuscripts have been fully peer reviewed, but should not be considered the official version of record. They are accessible to all readers and citable by the Digital Object Identifier (DOI®). "Just Accepted" is an optional service offered to authors. Therefore, the "Just Accepted" Web site may not include all articles that will be published in the journal. After a manuscript is technically edited and formatted, it will be removed from the "Just Accepted" Web site and published as an ASAP article. Note that technical editing may introduce minor changes to the manuscript text and/or graphics which could affect content, and all legal disclaimers and ethical guidelines that apply to the journal pertain. ACS cannot be held responsible for errors or consequences arising from the use of information contained in these "Just Accepted" manuscripts. 


\title{
Dynamics, Miscibility, and Morphology in Polymer:Molecule Blends: The Impact of Chemical Functionality
}

\author{
Khanh Do, ${ }^{\dagger, *}$ Chad Risko, ${ }^{\S} *$ John E. Anthony, ${ }^{\S}$ Aram Amassian, ${ }^{\ddagger}$ and Jean-Luc Brédas ${ }^{\ddagger, \dagger, *}$ \\ ${ }^{\dagger}$ School of Chemistry and Biochemistry \& \\ Center for Organic Photonics and Electronics (COPE) \\ Georgia Institute of Technology \\ Atlanta, Georgia, 30332-0400, USA \\ ${ }^{\ddagger}$ Physical Sciences and Engineering Division \\ Solar \& Photovoltaics Engineering Research Center \\ King Abdullah University of Science and Technology \\ Thuwal, 23955-6900, Kingdom of Saudi Arabia \\ ${ }^{\S}$ Department of Chemistry \& \\ Center for Applied Energy Research (CAER) \\ University of Kentucky \\ Lexington, Kentucky, 40506, USA
}

\author{
*Corresponding authors: \\ chad.risko@uky.edu; jean-luc.bredas@kaust.edu.sa




\begin{abstract}
.
In the quest to improve the performance of organic bulk-heterojunction solar cells, many recent efforts have focused on developing molecular and polymer alternatives to commonly used fullerene acceptors. Here, molecular dynamics simulations are used to investigate polymer:molecule blends comprised of the polymer donor poly(3-hexylthiophene) (P3HT) with a series of acceptors based on trialkylsilylethynyl-substituted pentacene. A matrix of nine pentacene derivatives, consisting of systematic chemical variation both in the nature of the alkyl groups and electron-withdrawing moieties appended to the acene, is used to draw connections between the chemical structure of the acene acceptor and the nanoscale properties of the polymer:molecule blend, which include: polymer and molecular diffusivity, donor-acceptor packing and interfacial (contact) area, and miscibility. The results point to the very significant role that seemingly modest changes in chemical structure play during the formation of polymer:molecule blend morphologies.
\end{abstract}




\section{Introduction.}

Organic photovoltaic (OPV) cells are of academic and commercial interest due to their potential for flexible, light-weight, and large-scale solar energy harvesting applications derived from low-cost, high-throughput manufacturing techniques. ${ }^{1-4}$ The most prevalent OPV photoactive layer, referred to as a bulk heterojunction (BHJ), is comprised of a solutionprocessed organic donor:acceptor blend that relies on inherently poor miscibility between the donor and acceptor to form nanoscale phase-separated domains. ${ }^{1}$ The donor and acceptor materials can include $\pi$-conjugated polymers and/or (small) molecules and oligomers, ${ }^{5-6}$ with blends based on polymer donors and fullerene-derivative acceptors typically showing the highest photovoltaic performance. ${ }^{7}$

Fullerene derivatives, particularly [6,6]-phenyl- $\mathrm{C}_{61}$-butyric acid methyl ester $\left(\mathrm{PC}_{61} \mathrm{BM}\right)$ and its $\mathrm{C}_{70}$ analog $\left(\mathrm{PC}_{71} \mathrm{BM}\right)$, possess many properties that lead to high OPV performance, including facile reduction, ${ }^{8}$ good electron-transport properties, ${ }^{9-10}$ three-dimensional charge-carrier transport, and sufficient phase separation with many donor polymers in solution-cast thin films. ${ }^{11}$ Consequently, most efforts in the design of donor systems, and in particular narrow optical-gap conjugated polymers, ${ }^{12}$ aim for complementary properties with these fullerenebased acceptors such that the electronic and optical properties of the device are optimized. This includes maximizing: (i) photon absorption within the full solar spectrum; (ii) open-circuit voltage $\left(V_{\mathrm{OC}}\right)$ by controlling (to a first approximation) the offset between the ionization potential of the donor and the electron affinity of the fullerene; and (iii) charge-transfer state energy at the polymer/fullerene interface. Beyond these properties, the phase-separation thermodynamics and kinetics need to be optimized to control the thin-film morphology, as the latter directly impacts charge-carrier generation, migration, recombination, and collection. As a 
result, a large parameter space must be considered for BHJ OPV optimization, including many intrinsic details at the molecular scale. Unfortunately, fullerene derivatives possess a number of drawbacks. For example, although much more costly, $\mathrm{PC}_{71} \mathrm{BM}$ has been employed in part to address the weak absorption of visible radiation by $\mathrm{PC}_{61} \mathrm{BM}$, which generally leads to higher OPV performance stemming from increased short-circuit current density $\left(J_{\mathrm{SC}}\right) .{ }^{13} \mathrm{In}$ addition, the large electron affinities of fullerene derivatives can result in suboptimum $V_{\mathrm{OC}}$ when blended with common conjugated polymers such as poly(3-hexylthiophene) (P3HT). ${ }^{14}$

Consequently, recent efforts have focused on developing non-fullerene acceptors to optimize material absorption, miscibility, and material electronic properties to maximize the versatility of selecting donor and acceptor pairs. ${ }^{14-27}$ Having a greater selection of donor:acceptor pairs can improve our basic understanding of how features in chemical structure affect each device characteristic, and in particular the formation of the BHJ morphology. Representative nonfullerene acceptors include naphthalene ${ }^{18}$ and perylene ${ }^{19}$ diimides, oligothiophenes, diketopyrrolopyrroles, vinazenes, rhodamines, and substituted pentacenes. ${ }^{14-17}$ Design strategies for these acceptors include: (i) modulating the electronic, redox, and optical properties via chemical substitution of electron-withdrawing groups and/or increasing the $\pi$ conjugation pathway; and (ii) influencing solubility/miscibility through substitution of pendant alkyl groups. These strategies are generating increased success, as power conversion efficiencies (PCE) over 7\% have now been achieved in polymer:molecule and all-polymer BHJ OPVs. ${ }^{20-26,28-29}$

It is well demonstrated that slight modifications in the chemical structure of organic electronic materials can lead to major changes in pristine and blend film morphologies and their subsequent performance. ${ }^{17,}$ 29-33 In many OPV cells incorporating new acceptors, limiting 
factors, when compared to their fullerene counterparts, include poor thin-film morphologies e.g., in the forms of excessively coarse phase separation or intimate mixtures with insufficient phase separation - and charge-carrier transport characteristics, both of which are a direct consequence of chemical functionality, processing conditions and formulation. While the latter two have been the subject of several experimental investigations, ${ }^{30-33}$ the former has been explored far less, especially in the context of non-fullerene acceptors and even less so via computational methods. Therefore, it is desirable to develop a better understanding of the relationships between chemical structure and morphology to improve the performance of nonfullerene acceptors. In drawing connections between acceptor chemical structure and blend microstructure, it is important to elucidate the morphological influences of the electronwithdrawing and alkyl groups, both of which are non-innocent components during film formation. Moreover, it is of special interest to untangle the steric and electrostatic effects these chemical groups may exert on their local environment.

Of particular relevance to this study is previous work by Shu and co-workers, who surveyed a variety of electron-deficient pentacenes as acceptors in BHJ devices with poly(3hexylthiophene) $[\mathrm{P} 3 \mathrm{HT}]$ acting as the donor material. ${ }^{34}$ Pentacene-based small molecules are easily amenable to synthetic substitution, which makes them good candidates for comprehensive investigations (Figure 1). Device $V_{\mathrm{OC}}$ and $J_{\mathrm{SC}}$ were found to vary with the electron-withdrawing group and alkyl group substitution, respectively, and correlate with crystal structure packing motifs of the pentacene-based material. ${ }^{34}$

Here, we systematically evaluate, through a series of multi-scale molecular simulations, the structure-function relationships of these pentacene-based acceptors in P3HT to clarify how the chemical structure of the substituted pentacenes influences the blend morphology, which in 
turn affects OPV performance. We focus specifically on a series of 6,13bis(trialkylsilylethynyl)-substituted pentacenes, hereafter simply referred to as acenes, shown in Figure 1. The acene structures are varied by the alkyl groups appended to the silicon atoms including triethyl (TES), tri-isopropyl (TIPS), and tri-cyclopentyl (TCPS) - and by substitution on the $\beta$-position on the pentacene core with an electron-withdrawing group, either trifluoromethyl $\left(-\mathrm{CF}_{3}\right)$ or cyano $(-\mathrm{CN})$, while the unsubstituted core is denoted as $-\mathrm{Pn}$.
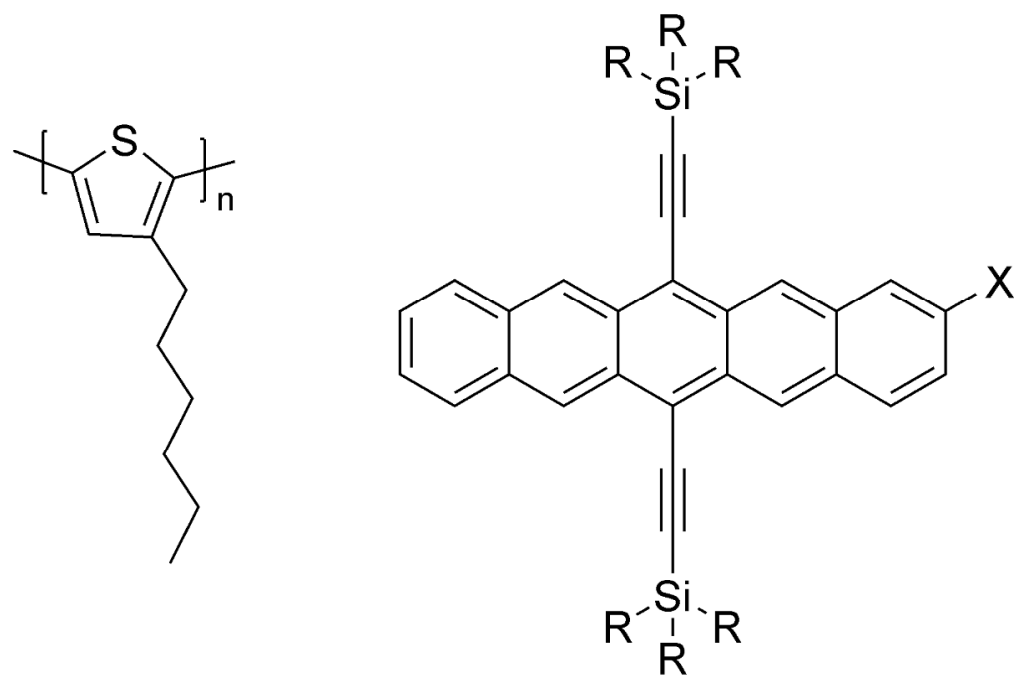

$$
\begin{aligned}
& \mathrm{R}=\text { ethyl, propyl, cyclopentyl } \\
& \mathrm{X}=\mathrm{H}, \mathrm{CF}_{3}, \mathrm{CN}
\end{aligned}
$$

Figure 1. Chemical structures of poly(3-hexylthiophene) (left) and trialkylsilylethynylsubstituted pentacene (right).

In our molecular modeling approach, we perform atomistic molecular dynamics (MD) simulations to obtain target structural distributions, which are then used to derive coarsegrained (CG) potentials following the work of Huang et al. ${ }^{35} \mathrm{CG}$ simulations drastically reduce the degrees-of-freedom involved in modeling large systems, which is essential to studying 
systems with length scales approaching that of the device and for timescales that ensure the possibility of phase separation of the blend component materials. ${ }^{35-38}$ These modeling advantages allow us to build structure-morphology relationships that are relevant to device properties, such as donor-acceptor morphology, miscibility, and interfacial area, and may inform future designs of donor/non-fullerene acceptor combinations. In our mapping scheme, see Figure 2, we choose to represent the P3HT monomer and acene molecule with the fewest CG particles possible while retaining the molecular shape and chemical nature of the materials. In this way, we can discern trends in morphological properties and link them to specific features of the chemical structure.
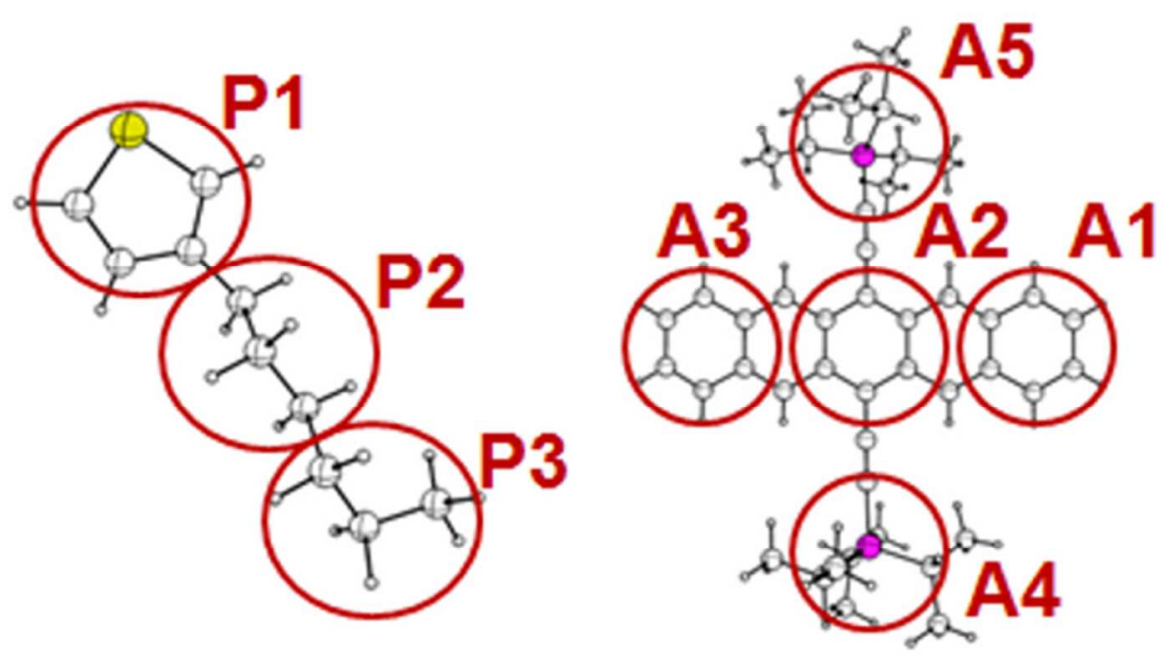

Figure 2. Mapping scheme used in the coarse-grained (CG) simulations of P3HT and the acenes (TIPS-Pn as the example). CG sites are constructed from the centers-of-mass of the encircled atoms. A1 is the site on the acene backbone where the electron-withdrawing group is attached. 


\section{Computational Methodology.}

Atomistic MD simulations of systems containing pure P3HT, pure acene, and mixed P3HT:acene were performed to obtain target microstructures for the coarse-graining procedure. The pure P3HT system contained 40 decamer chains, which are completely regioregular, and the pure acene systems each contained 256 molecules. The mixed P3HT:acene systems each contained 40 decamer P3HT chains and a varying number of acene molecules, depending on their type, to construct an approximate 1:1 wt/wt ratio mixture; larger system sizes gave nearly identical structural distributions and thermodynamic properties. The All-Atom Optimized Potentials for Liquid Simulations (OPLS-AA) ${ }^{39}$ force field was used for the material systems with some modifications, on the basis of DFT calculations, ${ }^{40}$ in the partial charges of the thiophene and in inter-monomer dihedral potentials of $\mathrm{P} 3 \mathrm{HT}$ to account for the conjugation of the chain backbone. $^{35,} 41$ The atomistic MD simulations were performed with a random initial configuration in a cubic box with periodic boundary conditions and in the melt (melting points of P3HT and TIPS-Pn are $511 \mathrm{~K}$ and $549 \mathrm{~K}$, respectively) ${ }^{42}$ at $550 \mathrm{~K}$ and 1 atm (NPT ensemble), using a Nosé-Hoover thermostat ${ }^{43}$ and Nosé-Hoover barostat, ${ }^{44}$ respectively. The SHAKE algorithm $^{45}$ was used to constrain $\mathrm{C}-\mathrm{H}$ bonds with fixed length. The cut-off distance for shortrange non-bonded interactions (Coulomb and Lennard-Jones) was $12.0 \AA$. Long-range electrostatic interactions were computed using the Particle-Particle Particle-Mesh (PPPM) method. ${ }^{46}$ A timestep of 1.5 fs was used. Simulations were performed for a total time of at least $10 \tau_{2}$ and varied between $25-75 \mathrm{~ns}$ depending on the type of acene in the mixture; the relaxation time $\tau_{2}$ is a measure of the time scale for chain reorientation, and is computed by fitting the autocorrelation function of the unit vector $\mathbf{u}(t)$ between the polymer chain ends to the equation $<P_{2}[\mathbf{u}(t) \cdot \mathbf{u}(0)]>\approx \exp \left(-t / \tau_{2}\right)$, where $P_{2} \equiv\left(3 x^{2}-1\right) / 2$ is the second-order Legendre polynomial. 
Distribution functions and quantities of interests were computed from trajectories corresponding to the latter $5 \tau_{2}$ of each simulation, and were checked that they did not vary systematically with time.

The parameters for $\mathrm{CG}$ simulations were derived using the iterative Boltzmann inversion (IBI) method following the work of Huang et al., ${ }^{35}$ see Equation 1, where a set of potentials $\left[U_{i}(x)\right]$ describing bond lengths, bond angles, dihedral angles, improper dihedral angles, and non-bonded interactions between $\mathrm{CG}$ particles were iteratively optimized such that the structural distributions of the CG system matched that of the atomistic system, i.e., $P_{i}(x)=P_{\text {target }}(x)$. The $a_{i}$ parameter is used to control convergence and varies between 0 and 1. All optimized CG potentials and structural distributions are reported in the Supplementary Information (SI). The initial energy function used is shown in Equation 2.

$$
\begin{gathered}
U_{i+1}(x)=U_{i}(x)+a_{i} k_{\mathrm{B}} T \ln \left[\frac{P_{i}(x)}{P_{\text {target }}(x)}\right] \\
U_{0}(x)=-k_{\mathrm{B}} T \ln \left[P_{\text {target }}(x)\right]
\end{gathered}
$$

The CG particles were constructed using the centers-of-mass of groups of atoms as shown in Figure 2. The simulations to optimize the CG potentials were performed at constant volume and $550 \mathrm{~K}$ in an NVT ensemble. After convergence, the CG potentials were scaled linearly following Equation 3 in order to match the density from atomistic simulations at the same thermodynamic conditions. The scaling parameter $b_{i j}$ was chosen to reach a $\leq 2 \%$ error in the density. The P3HTP3HT and acene-acene CG interaction potentials were optimized using the pure P3HT and pure acene systems, respectively. The P3HT-acene CG interaction potentials were optimized using the 
mixed P3HT:acene systems while keeping the P3HT-P3HT and acene-acene potentials fixed as obtained from the pure systems.

$$
\Delta U_{j k}(r)=b_{j k}\left(1-\frac{r}{r_{\text {cut }}}\right), r \leq r_{\text {cut }}
$$

Having systematically coarse-grained the P3HT:acene mixtures, we performed CG simulations of approximately 1:1 wt/wt ratio mixtures, with each simulation containing approximately 100,000 particles at $c a .25 \mathrm{~nm}$ length scales. The blend ratio simulated here is equivalent to that used in reported devices. ${ }^{34}$ The chain length was 48 monomers, which corresponds to a molecular weight of about $8 \mathrm{kDa}$. Simulations of significantly longer chains, which would be more relevant to actual devices, were limited by computational feasibility. The CG simulations were performed at $550 \mathrm{~K}$ for $120 \mathrm{~ns}$ and then cooled from $550 \mathrm{~K}$ to $300 \mathrm{~K}$ over $200 \mathrm{~ns}$ to compare the impact of temperature on the miscibility of each blend. This was followed by $10 \mathrm{~ns}$ simulations at $300 \mathrm{~K}$. Initial configurations were random. A timestep of $5.0 \mathrm{fs}$ was used. All simulations were performed using LAMMPS $^{47}$ (see lammps.sandia.gov) and the Shaheen Blue Gene/P Supercomputer at KAUST (see ksl.kaust.edu.sa).

\section{Results and Discussion.}

As noted earlier, the matrix of nine blends for our simulation studies comprise pentacenes substituted with varying electron-withdrawing and trialkylsilylethynyl groups (Figure 1). The electron-withdrawing group is varied between a cyano $(-\mathrm{CN})$ and trifluoromethyl $\left(-\mathrm{CF}_{3}\right)$ group, in addition to the unsubstituted case (-Pn). The alkyl chains on the silylethynyl arms are varied 
among tri-ethyl (TES), tri-isopropyl (TIPS), and tri-cyclopentyl (TCPS) groups. It is expected that electron-withdrawing group strength and alkyl group size will control the blend miscibility and influence intermolecular packing.

It is instructive to first compare the electron-withdrawing group polarity - and its contribution to the dipole moment of the acene molecule - as it will impact the structure-property relationships. Using the empirically-derived OPLS charges, ${ }^{39}$ dipole moments of $2.5 \mathrm{D}$ and $2.8 \mathrm{D}$ are obtained for the "C- $\mathrm{CF}_{3}$ " and "C-CN" group, respectively. Meanwhile, the "C-H" group in the unsubstituted acene has a dipole moment of $0.6 \mathrm{D}$. The polarity of these electron-withdrawing groups (or lack thereof) - the order of which is emphasized for our discussion below - leads to a range via energy minimization (in increasing order) of $0.0-1.0 \mathrm{D}, 2.5-2.7 \mathrm{D}$, and $3.0-3.5 \mathrm{D}$ for the unsubstituted, $\mathrm{CF}_{3^{-}}$, and $\mathrm{CN}$-substituted acenes, respectively. Although partial charges obtained from quantum-chemical calculations would give more specific values with respect to the chemical structure of the acene, we expect the qualitative trends in polarity discussed here using OPLS charges to remain intact.

We first examine the connection between chemical structure and molecular dynamics, as characterized by diffusivity, of the simulated atomistic systems. The diffusivity of P3HT and the acenes in their pure and mixed systems is expected to affect the BHJ microstructure during solution-casting and post-production thermal annealing; extensive solution studies are ongoing and are the focus of future work. Figure 3 shows a comparison of the orientational and translational diffusivities of P3HT (using the thiophene center-of-mass) in the pure and mixed systems. The orientational diffusion coefficient $\alpha$, which is the inverse of $\tau_{2}$, is obtained by fitting the chain auto-correlation function to the equation $\left\langle P_{2}[\mathbf{u}(t) \cdot \mathbf{u}(0)]>\approx \exp \left(-t / \tau_{2}\right)\right.$ as described in the 
Computational Methodology section. The translational diffusion coefficient $D$ is obtained by fitting the mean square displacement to the equation $\left\langle r^{2}(t)>\approx 6 D t\right.$.

Both orientational and diffusional types of diffusion decrease with increasing alkyl group size and with electron-withdrawing group strength, with the P3HT diffusivity being generally smaller in mixtures than in the pure polymer; the lone exception is TES-Pn (TES is the smallest alkyl substituent considered and the acene has no electron-withdrawing group). In addition, the decrease in diffusivity, which increases with increasing strength of the electron-withdrawing group, is more dramatic when the alkyl group size is smaller, i.e., the variation in diffusivity is more pronounced for TES-acenes than for TIPS- and TCPS-acenes. The trends here for P3HT diffusivity in pure and mixed systems are likewise observed for the acenes, see Figure S1. 

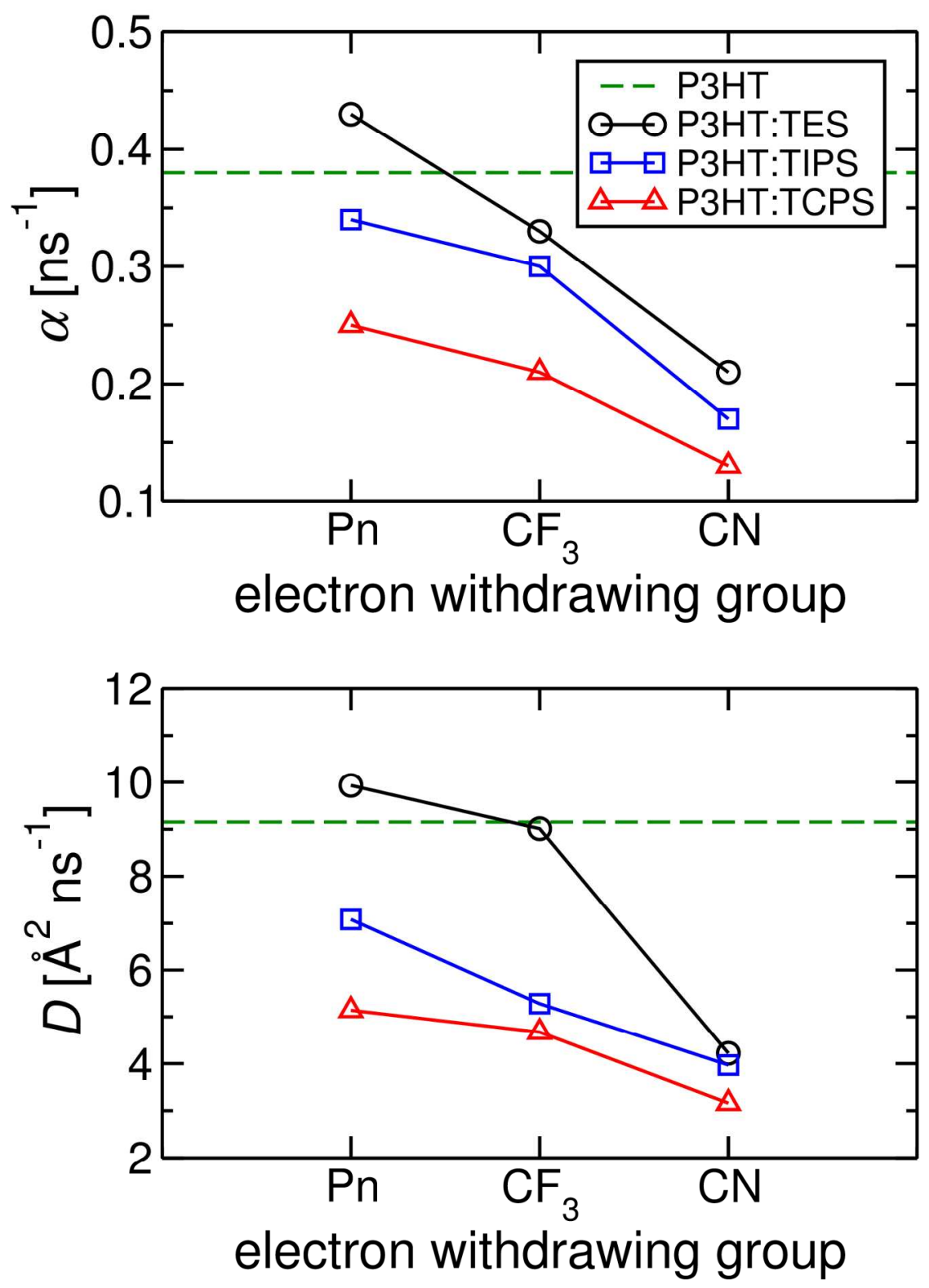

Figure 3. P3HT diffusivity in pure and mixed systems determined from atomistic NPT simulations at $550 \mathrm{~K}$ and $1 \mathrm{~atm}$. The coefficients $\alpha$ and $D$ correspond to orientational (top plots) and translational (bottom plots) diffusion, respectively.

We next detail the nature of the interactions between P3HT and the acenes, which impacts the diffusive properties of the blends and, as we will show, their miscibility; importantly, the relative interaction among the $\mathrm{P} 3 \mathrm{HT}$ and acene will govern the distribution of configurations at the 
donor-acceptor interface and, in turn, the energy landscape and critical electronic processes relevant to charge generation and solar cell operation. ${ }^{48-50}$ Figure 4 shows the radial distribution functions (RDFs), $g(r)$, among pairs of sites, defined by taking the centers-of-mass of a thiophene in a P3HT oligomer (P1) and three (distinct) six-carbon rings of the pentacene backbone (A1-A3); note that A1 is the site nearest to the electron-withdrawing group. The RDF measures the probability of finding a site some distance away from a reference site. The location and height/sharpness of the first-order peak (at small distances) indicate the closeness and (energetic) strength, respectively, in the packing of the sites involved. The appearance of secondary and higher-order peaks indicate higher degree of order.

We start with the impact of the alkyl group substitution. The RDFs in TES-acene mixtures contain the highest first-order peaks (Figures $4 \mathrm{a}, \mathrm{d}, \mathrm{g}$ ) relative to their TIPS (b, e, h) and TCPS $(\mathrm{c}, \mathrm{f}, \mathrm{i})$ analogues, indicating that the thiophene rings approach the pentacene backbones more readily, owing to minimal steric hindrance of the ethyl groups. The first-order peaks for the TIPS-acene (Figures 4 b, e, h) and TCPS-acene mixtures (Figures 4 c, f, i) show marginal difference, hence the steric bulk of the isopropyl and cyclopentyl groups similarly affect the interactions between the thiophene and pentacene backbones. 


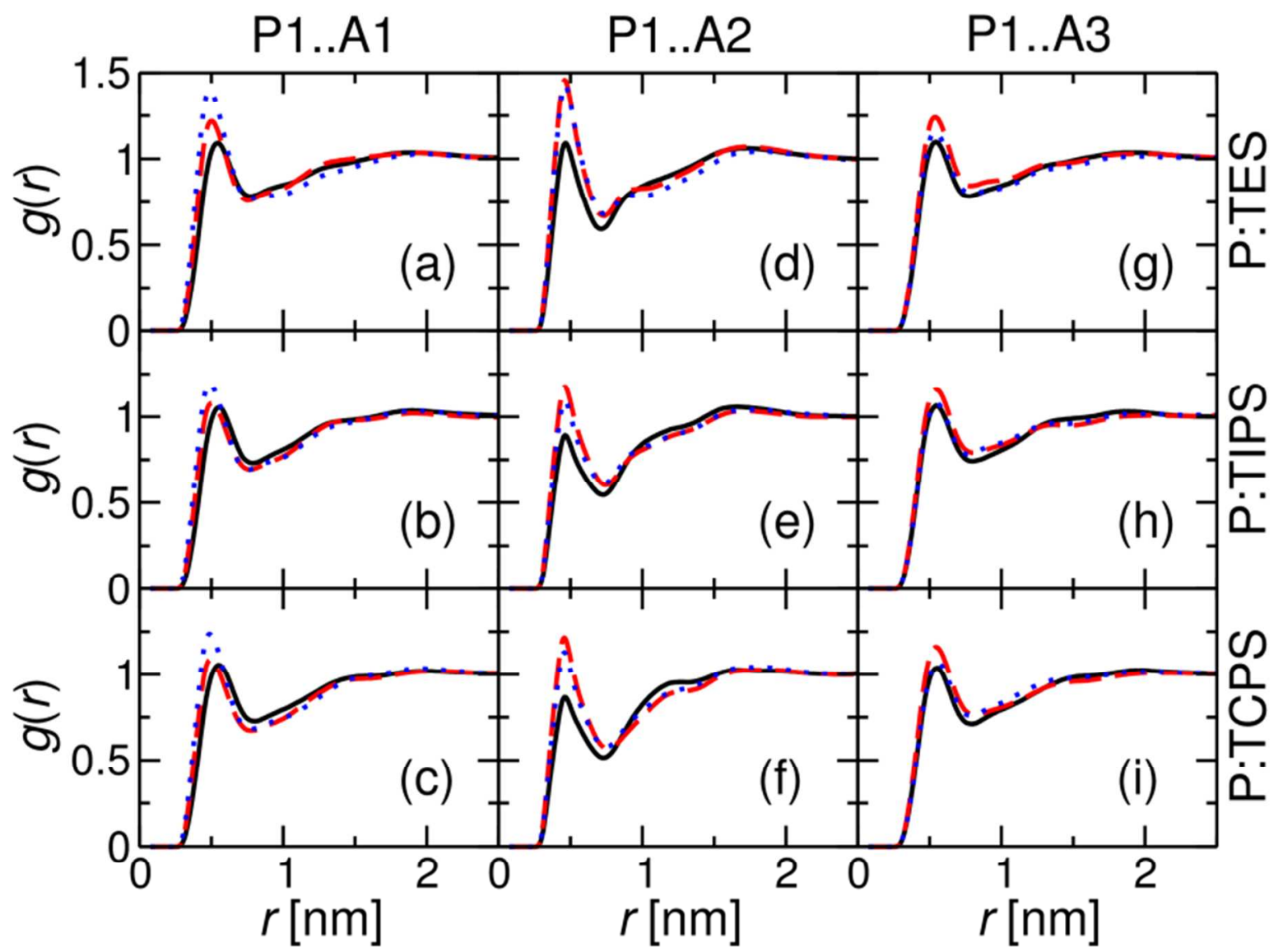

Figure 4. Radial distribution functions, $g(r)$, among non-bonded sites P1 of P3HT and A1-A3 of the acenes determined from atomistic NPT simulations of P3HT:acene mixtures at $550 \mathrm{~K}$ and 1 atm. Solid, dashed, and dotted lines denote the unsubstituted, $\mathrm{CF}_{3^{-}}$, and $\mathrm{CN}$-acene, respectively. See Figure 2 for site definitions.

We now turn to the influence of the electron-withdrawing group. The $\mathrm{CF}_{3}$ and $\mathrm{CN}$ substitutions systematically give rise to slightly closer and stronger contacts among the thiophene rings and pentacene backbones, characterized by the (mostly) higher first-order peaks when compared to the unsubstituted case across the RDFs. This feature stems in part from the thiophene polarity, with dipole-dipole interactions leading to the stronger contacts between the thiophene rings and the substituted polar pentacene backbones, see for instance the P1..A1 RDFs in Figures 4 a-c. Consequently, the P1..A3 RDF peaks for the $\mathrm{CN}$-acenes (Figures $4 \mathrm{~g}$-i) decrease to the 
equivalence of the unsubstituted case, as the thiophene predominantly settles near A1 and A2. The P1..A2 RDFs (Figures 4 d-f), when compared with the P1..A1 RDFs, reveal the relative interplay of the electron-withdrawing group polarity versus steric bulk: The peaks in the P1..A2 RDFs are clearly sharper than those in P1..A1 RDFs for the $\mathrm{CF}_{3}$-acenes (dashed lines), indicating that the steric hindrance of the tetrahedral $\mathrm{CF}_{3}$ group outweighs its polar attraction in packing with neighboring thiophenes. On the other hand, the peaks for the $\mathrm{CN}$-acenes (dotted lines) in P1..A1 and P1..A2 RDFs are roughly the same, which shows that the polar attraction of the CN group outweighs the extra steric hindrance when compared to the unsubstituted system. Thus, the trends in diffusivity as a function of electron-withdrawing group discussed above can be directly linked to the thiophene-pentacene interactions.

The trends in thiophene-pentacene interactions discussed so far reveal polar-driven interactions. We now examine the RDFs between sites on the P3HT hexyl-chains and the pentacene backbones, plotted in Figure 5; we note that these interactions are relevant to solar-cell performance as they are likely to minimize the important electronic couplings between the conjugated units of P3HT and the acenes. The first-order P3...A1 RDF peaks are clearly sharp for the unsubstituted acenes (solid lines), while the peaks are smaller for $\mathrm{CF}_{3^{-}}$and $\mathrm{CN}$-acenes (dashed and dotted lines, respectively), due to a combination of the steric bulk and polarity of the electron-withdrawing groups. Furthermore, the first-order peaks and corresponding valleys for $\mathrm{CF}_{3}$-acenes are flatter when compared to $\mathrm{CN}$-acenes, which points to a lesser degree of order stemming from the more pronounced steric bulk of the tetrahedral $\mathrm{CF}_{3}$. The P3..A2 and P3..A3 RDFs (Figure S2) are nearly indistinguishable as a function of the chemical structure, suggesting that the alkyl group size does not affect the interactions between the hexyl-chain of P3HT and 
the pentacene backbone. Note that the RDF trends obtained from the simulations at $550 \mathrm{~K}$ are expected to be more pronounced at lower (room) temperatures.

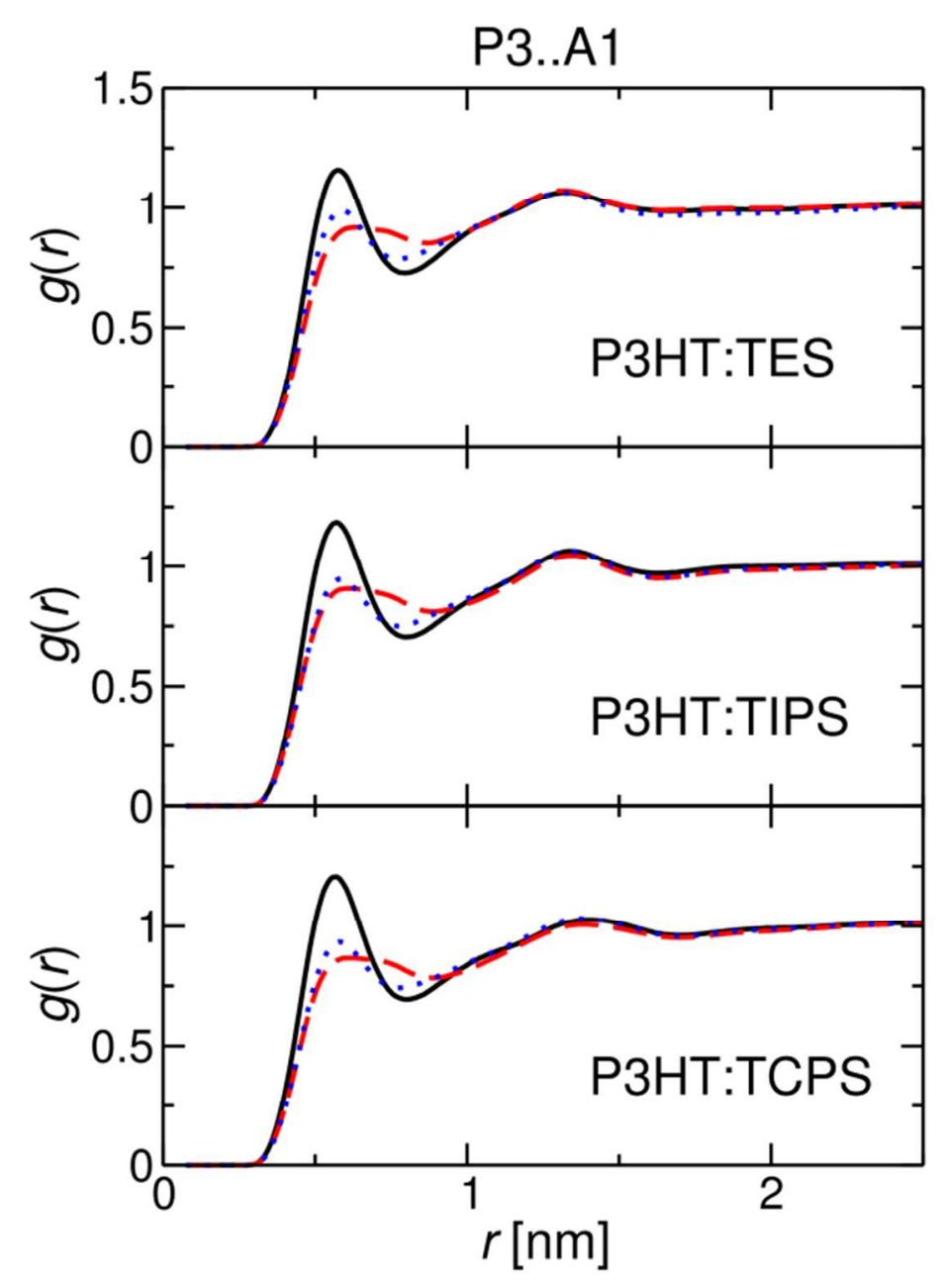

Figure 5. Radial distribution functions, $g(r)$, among non-bonded sites P3 of P3HT and A1 of the acenes determined from atomistic NPT simulations of P3HT:acene mixtures at $550 \mathrm{~K}$ and $1 \mathrm{~atm}$. Solid, dashed, and dotted lines denote the unsubstituted, $\mathrm{CF}_{3^{-}}$, and $\mathrm{CN}$-acene, respectively. See Figure 2 for site definitions.

The above discussion comparing P3HT-P3HT, acene-acene, and P3HT-acene interactions with elaboration on thiophene-pentacene and hexyl-pentacene interactions is prerequisite to drawing 
connections between chemical structure and miscibility and/or morphology. Thus, we now shift our focus to $\mathrm{CG}$ simulations of P3HT:acene blends in order to build such structure-property relationships. As mentioned in the Computational Methodology section, we performed CG simulations of P3HT:acene blends at $550 \mathrm{~K}$ and at $300 \mathrm{~K}$ (by cooling from $550 \mathrm{~K}$ over $200 \mathrm{~ns}$ ).

To quantify miscibility, the normalized demixing parameter $\bar{\psi}_{n}$ was determined at both thermodynamic conditions, see Figure S3 for data at $550 \mathrm{~K}$; however, we opt to highlight the demixing parameter as a function of temperature over the course of cooling as shown in Figure 6. The demixing parameter is defined in Equation 4, where $n^{3}$ is the total number of cubes into which the system is divided, $\rho_{i}$ is the density of the $i$-th cube, and $\rho$ is the global density of the system. $^{51}$

$$
\bar{\psi}_{n} \equiv \frac{1}{n^{3}} \sum_{i=1}^{n^{3}}\left|\frac{\rho_{i}}{\langle\rho\rangle}-1\right|
$$

In principle, the lower limit of $\bar{\psi}_{n}$ is zero, which corresponds to a completely uniform phase where the local and global densities are the same. The upper limit of $\bar{\psi}_{n}$ is $2 V_{2} /\left(V_{1}+V_{2}\right)$, where $V_{1}$ and $V_{2}$ are the volumes of the individual pure systems, and indicates two completely separated phases. However, in practice $\bar{\psi}_{n}$ cannot be zero due to the fluctuating local densities of each cube and is proportional to the standard deviation of the fluctuations, which decreases with $n$. More information on the demixing parameter can be found in Ref. 51. Here, $\bar{\psi}_{n}$ was determined with $n=12$ by dividing the simulation box into $n^{3}$ cubes with length $l_{\text {cube }}=L_{\text {box }} / n$, which is $c a$. 20 $\AA$ A. Figure 6 shows a comparison of $\bar{\psi}_{n}$ for the P3HT:acene blends during the course of $200 \mathrm{~ns}$ 
where the temperature was cooled from $550 \mathrm{~K}$ to $300 \mathrm{~K}$. Each blend started from an initial homogeneously mixed system.

The first notable trend is that acenes with larger alkyl groups result in less mixing with P3HT. The exception is TES- $\mathrm{CF}_{3}$, which is less mixed than its unsubstituted and CN-substituted analogs. These features suggest that steric hindrance, coming from either the alkyl or electronwithdrawing groups, disrupts close packing and induces less mixing. On the other hand, the polarity of the electron-withdrawing group enhances mixing. The demixing parameter decreases on going from the unsubstituted TIPS- and TCPS-acenes (squares and triangles, respectively) to the $\mathrm{CF}_{3}$ - and $\mathrm{CN}$-substituted analogs. Once again, $\mathrm{TES}-\mathrm{CF}_{3}$ is an exception in addition to TESCN. In fact, the miscibility of P3HT:TES-acene blends (circles) decreases with the steric hindrance of the electron-withdrawing group, suggesting that steric effects of the electronwithdrawing group dominate in controlling miscibility when the alkyl group is small. Conversely, steric effects of the alkyl groups dominate in controlling miscibility when the alkyl groups are sufficiently larger, e.g., isopropyl and cyclopentyl. In the latter case, variations in miscibility are to a secondary degree controlled by the electron-withdrawing group strength. The trends in P3HT:acene miscibility presented here can be directly attributed to the P1..A1 interactions between thiophene and the pentacene backbone discussed above. Hence, clear connections between the variation in P3HT:acene miscibility can be made to specific intermolecular interactions due to the chemical structure. 

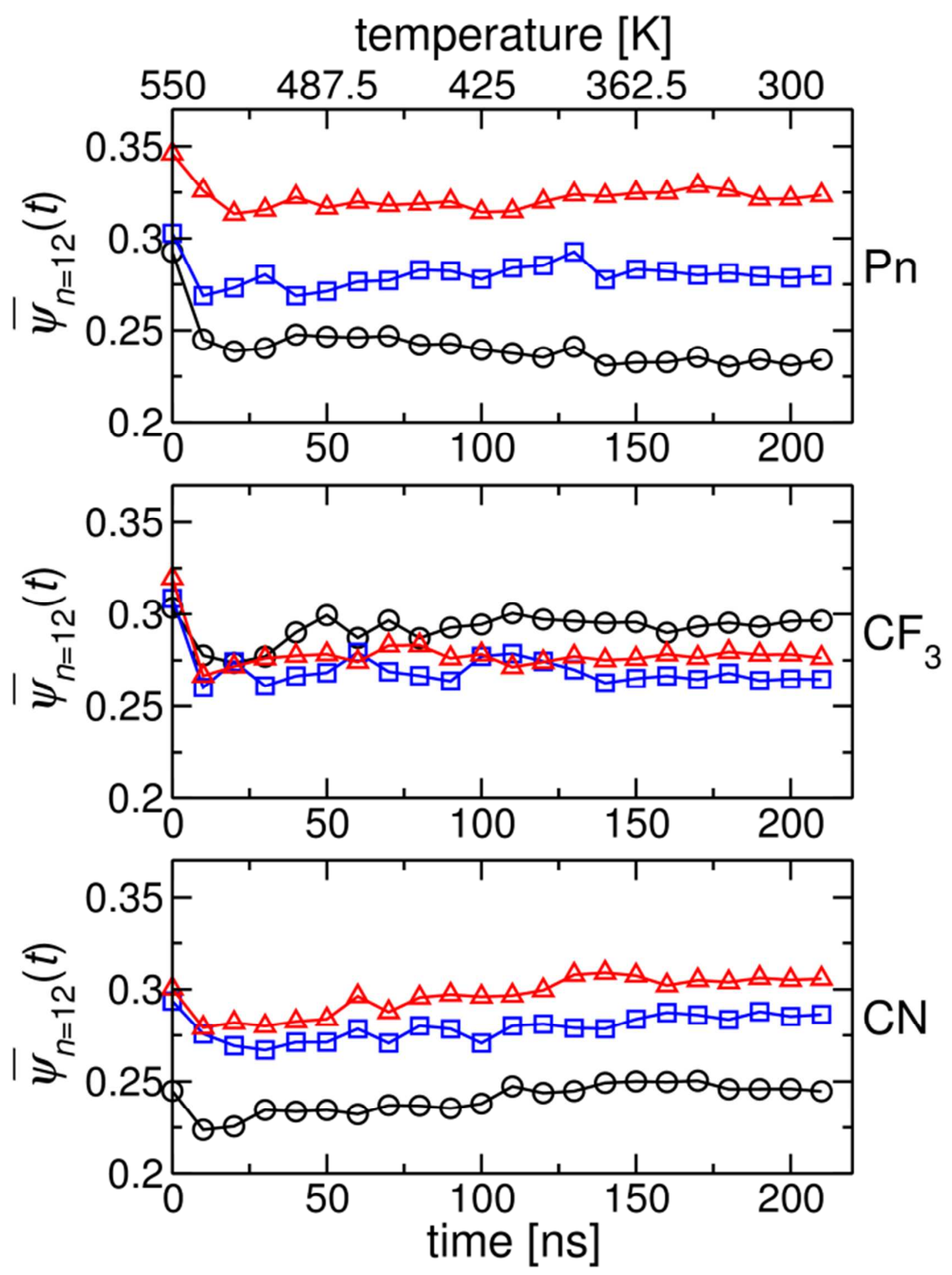

Figure 6. Normalized demixing parameter $\bar{\psi}_{n}(n=12)$ for P3HT:acene blends determined from CG simulations where the system is cooled from $550 \mathrm{~K}$ to $300 \mathrm{~K}$ over the course of $200 \mathrm{~ns}$. Circles, squares and triangles denote TES-, TIPS- and TCPS-acenes, respectively. 
The discussion of miscibility based on the demixing parameter can vary with the number of cells $n^{3}$ used in the calculation. Although trends in miscibility can be deduced from a comparison of the demixing parameter in P3HT:acene blends, a more robust parameter that is directly relevant to experiment is desirable. To this end, we implemented a simple discretization procedure similar to that in Ref. 37 to approximate the interfacial area between "phases" of P3HT and acene. Each blend system at $300 \mathrm{~K}$ is divided into $N=48$ cubes, giving a cube size of $\approx 5 \AA$ (roughly the volume of a CG particle when taking the average distance at the onset of the first-order peaks in their RDFs with other particles in the system). Each cube is then assigned as a blue (P3HT) or yellow (acene) cube, see Figure 7, depending on which material has the majority volume in the cube. The interfacial area is then computed between cubes of different color and is normalized by the total area between cubes, therefore giving a relative percent value. 

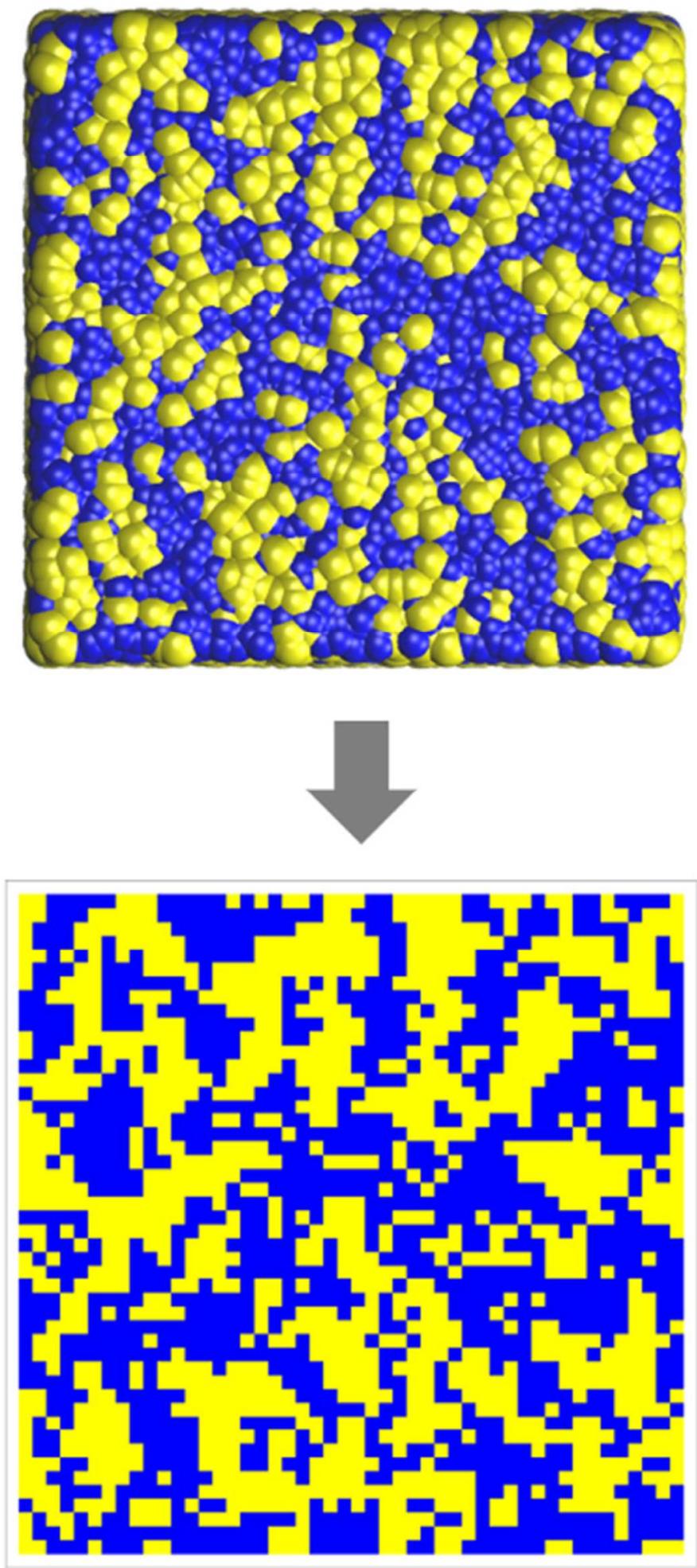

Figure 7. Illustration of the discretization procedure used to approximate the interfacial area among the P3HT (blue) and acene (yellow) "phases." Each cube is assigned to P3HT or acene depending on which material has the majority volume in the cube. 
A comparison of the relative interfacial area for the P3HT:acene blends is shown in Figure 8. The trends in interfacial area parallel those deduced from the demixing parameter, see Figure 6, namely that acenes with larger alkyl groups lead to lower miscibility and hence smaller interfacial area (rectangles in Figure 8). The trends for $\mathrm{CF}_{3}$-acenes are less clear (circle in Figure 8), which suggests that the miscibilities of these acenes are too similar for our simple discretization method to discern their order of interfacial area. According to the demixing parameter, TCPS $-\mathrm{CF}_{3}$ is expected to have an interfacial area in between those of its TES and TIPS analogues; however, the former has a slightly larger area than the latters. In general, the range of interfacial area (and miscibility) for these blends is relatively narrow, between 33 to $39 \%$, which means that any marked variations observed in BHJ thin-film morphology should be expected to arise from solubility differences in these materials and/or crystallization features, which are not likely captured in these CG simulations. Studying the solubility of P3HT:acene blends in solution and the effect of solvent on the formation of the blend morphology is the subject of our future work. We note that the ability to systematically control interfacial area, domain sizes, and interfacial phase mixing - i.e., the composition of the mixed phase layer at the interface between pure donor and acceptor domains - would allow better control of chargecarrier recombination, which is important for device properties such as $V_{\mathrm{OC}}{ }^{52}$

Recent works have used similar coarse-graining methods to investigate the optimal blending ratios of P3HT:PCBM and poly(2,5-bis(3-alkylthiophen-2-yl)thieno[3,2-b]thiophene [PBTTT]:PCBM blends. ${ }^{36-37}$ The P3HT:acene blends here at $\sim 1: 1 \mathrm{wt} / \mathrm{wt}$ ratio exhibit similarly high miscibility as those of P3HT:PCBM and PBTTT:PCBM at the same blend ratio. Given these similar miscibilities between the P3HT:acene blends and P3HT:PCBM, we expect that phase separation in the acene-blends will be led by crystallization (or the lack thereof) of P3HT 
and the acene molecules, as it is in PCBM-blends. ${ }^{33,53}$ For P3HT:PCBM blends, pure amorphous phases of the component materials are negligible; miscibility studies ${ }^{54-55}$ have shown three distinct phases: crystalline P3HT, crystalline PCBM, and mixed amorphous P3HT with significant concentrations of PCBM. Again, given that the miscibilities of the P3HT:acene blends are similar to that of P3HT:PCBM, we expect to see similar patterns in the types of phases present in the BHJ morphology. It should be stressed that any complete model describing the formation of the BHJ morphology should be able to capture the crystallization of the component materials. The coarse-graining methods used here are unlikely to reproduce precise crystal structures and unit-cell parameters given that hydrogen and $\pi$-interactions have been averaged out and that planar rings are represented as "spheres", which increases the steric bulk in their interactions. However, the aggregation of $\pi$-conjugated polymers in the bulk ${ }^{56}$ and solution $^{41}$ has been shown to reproduce correctly the lamellar packing in simulations using similar coarse-graining methods. In fact, the atomistic force field for P3HT used here is the same as that in Ref. 41, which lends support to the validity of our model. Studies examining the crystallization of P3HT and the acene molecules, and their behavior in solution are the subject of our future work. 


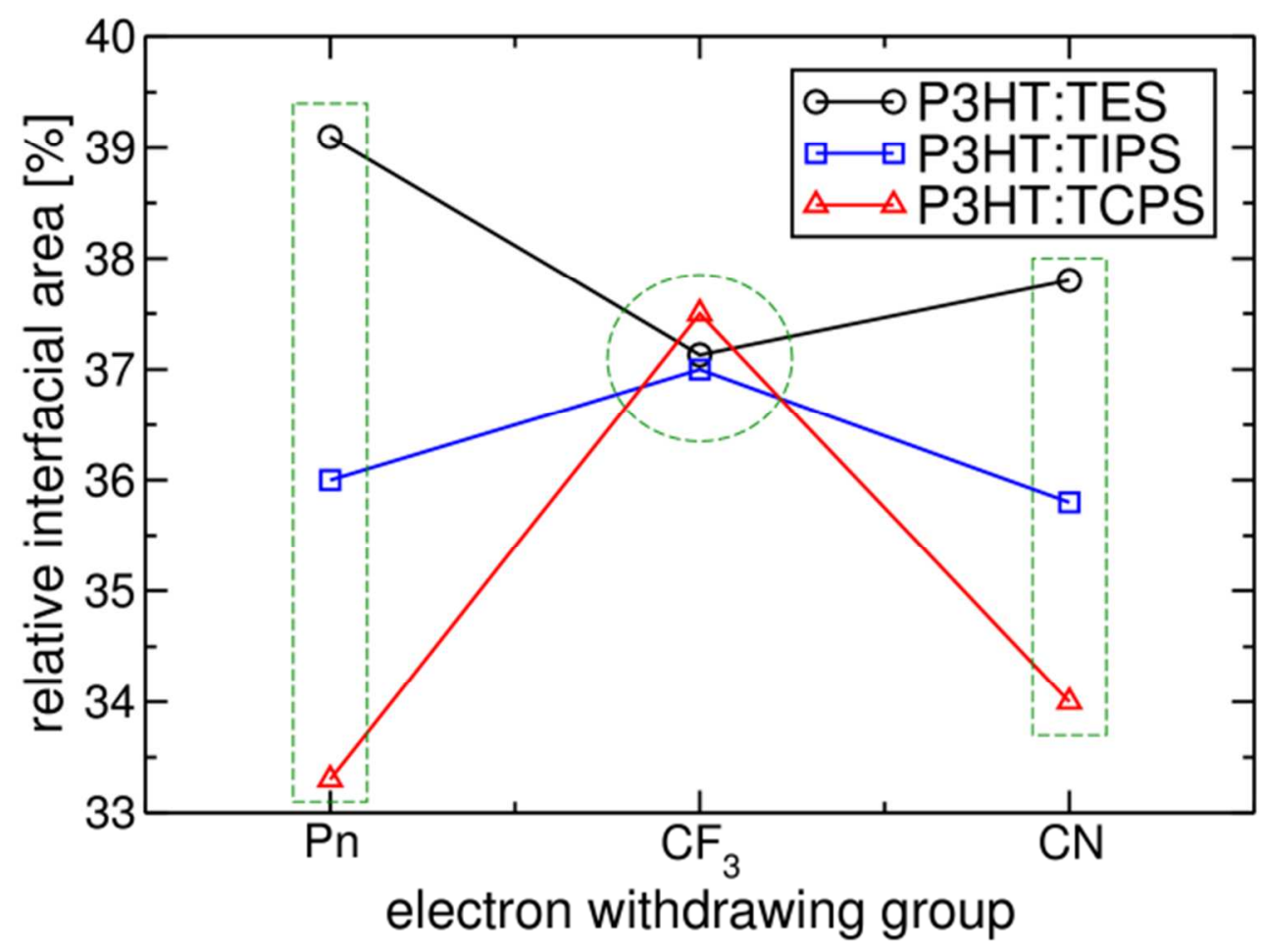

Figure 8. Relative interfacial area between P3HT (donor) and acene (acceptor) cubes computed from discretized models of the P3HT:acene blends at $300 \mathrm{~K}$.

So far, we have drawn connections linking the chemical structure of the acene with molecular diffusivity, donor-acceptor interactions, miscibility, and interfacial area in blends with P3HT. We now inspect the effect of miscibility on the structure of P3HT chains in the blend, namely the gyration radius, $R_{\mathrm{g}}$. Larger values of $R_{\mathrm{g}}$ indicate extended chains while lower values indicate folded or coiled chains. Figure 9 shows the average gyration radius as a function of the demixing parameter as determined from $10 \mathrm{~ns}$ of CG simulations at $300 \mathrm{~K}$ (after being cooled from $550 \mathrm{~K}$ ). The green arrow in Figure 9 highlights the positive relationship between the two parameters such that lower miscibility facilitates more extended chains in the blend. Although the range of $R_{\mathrm{g}}$ is narrow for our blends owing to the computationally-limited short chains, the trends are apparent and expected to become more pronounced when longer chains and larger system sizes are 
modeled. Extended chains in the blend morphology can be more favorable in solar-cell operation as they can bridge segregated ordered domains as "tie-chains," and facilitate more efficient pathways for charge carriers to reach electrodes. ${ }^{57}$

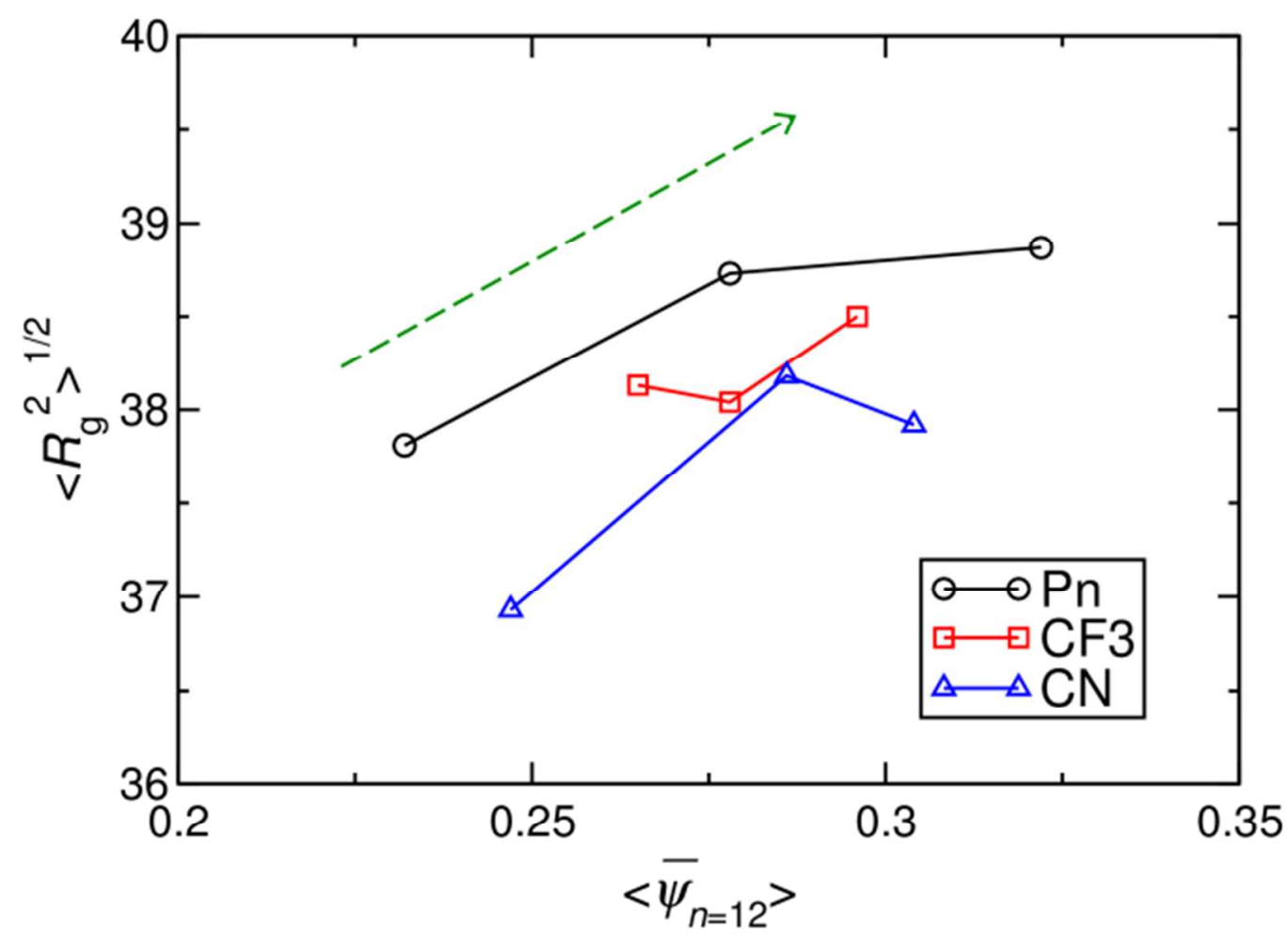

Figure 9. Relationship between the gyration radius of $\mathrm{P} 3 \mathrm{HT}$ and the demixing parameter in P3HT:acene blends determined from CG simulations at $300 \mathrm{~K}$.

\section{Conclusions.}

Molecular simulations of P3HT:acene blends have been performed to determine structuremorphology relationships relevant to organic BHJ solar-cell performance. By focusing on a matrix of nine acenes whose chemical structure is systematically varied in the nature of the alkyl groups and electron-withdrawing groups, connections between the chemical structure of the acene and P3HT and the molecular-scale properties within the blend can be made. 
The main results from our work are:

(i) Diffusivity is observed to generally decrease with size of the alkyl group and strength of the electron-withdrawing group on the acene.

(ii) Donor-acceptor interactions are enhanced by the electron-withdrawing group strength, but diminished primarily by steric bulk of the alkyl groups.

(iii) The blend miscibility generally decreases with alkyl group size and increases with electron-withdrawing group strength.

(iv) The trends in interfacial area between P3HT:acene "phases" reflect those in miscibility.

(v) Blends with lower miscibility contain more extended P3HT chains.

Importantly, the simulations employed here help to clarify molecular-scale mechanisms contributing to these materials properties. While our simulations consider only a small class of molecules, the systematic structure-property relationships detailed showcase the ability to systematically tailor organic electronic materials with specific morphological properties, as well as the power of molecular simulations to provide details that can relate to molecular design.

\section{Acknowledgments.}

This work was supported in part by the King Abdullah University of Science and Technology (KAUST) Office of Competitive Research Funds (Award No. FIC/2010/04), the KAUST Center for Advanced Molecular Photovoltaics (CAMP, Award No. KUS-C1-015-21), and the Office of Naval Research Global (Award No. N62909-15-1-2003). C.R. thanks the University of Kentucky Vice President for Research for start-up funds. 
Supporting Information Available: Atomistic and coarse-grained force-field parameters used in simulations of the pristine and blend systems are provided in detail. In addition, the coarsegraining procedure is detailed with plots showing goodness of fit. This material is available free of charge via the Internet at http://pubs.acs.org.

\section{References.}

1. Brabec, C. J.; Gowrisanker, S.; Halls, J. J. M.; Laird, D.; Jia, S.; Williams, S. P., Polymer-Fullerene Bulk-Heterojunction Solar Cells. Adv. Mater. 2010, 22, 3839-3856.

2. Darling, S. B.; You, F., The case for organic photovoltaics. RSC Adv. 2013, 3, 1763317648.

3. Scharber, M. C.; Sariciftci, N. S., Efficiency of bulk-heterojunction organic solar cells. Prog. Polym. Sci. 2013, 38, 1929-1940.

4. Søndergaard, R. R.; Hösel, M.; Krebs, F. C., Roll-to-Roll fabrication of large area functional organic materials. J. Polym. Sci., Part B: Polym. Phys. 2013, 51, 16-34.

5. Facchetti, A., Polymer donor-polymer acceptor (all-polymer) solar cells. Mater. Today 2013, 16, 123-132.

6. Walker, B.; Kim, C.; Nguyen, T.-Q., Small Molecule Solution-Processed Bulk Heterojunction Solar Cells. Chem. Mater. 2010, 23, 470-482.

7. He, Y.; Li, Y., Fullerene derivative acceptors for high performance polymer solar cells. Phys. Chem. Chem. Phys. 2011, 13, 1970-1983.

8. Xie, Q.; Perez-Cordero, E.; Echegoyen, L., Electrochemical detection of C60 and C70: Enhanced stability of fullerides in solution. J. Am. Chem. Soc. 1992, 114, 3978-3980.

9. Tummala, N. R.; Mehraeen, S.; Fu, Y.-T.; Risko, C.; Brédas, J.-L., Materials-Scale Implications of Solvent and Temperature on [6,6]-Phenyl-C61-butyric Acid Methyl Ester (PCBM): A Theoretical Perspective. Adv. Funct. Mater. 2013, 23, 5800-5813.

10. Wöbkenberg, P. H.; Bradley, D. D. C.; Kronholm, D.; Hummelen, J. C.; de Leeuw, D. M.; Cölle, M.; Anthopoulos, T. D., High mobility n-channel organic field-effect transistors based on soluble C60 and C70 fullerene derivatives. Synth. Met. 2008, 158, 468-472.

11. Cates, N. C.; Gysel, R.; Beiley, Z.; Miller, C. E.; Toney, M. F.; Heeney, M.; McCulloch, I.; McGehee, M. D., Tuning the Properties of Polymer Bulk Heterojunction Solar Cells by Adjusting Fullerene Size to Control Intercalation. Nano Lett. 2009, 9, 4153-4157.

12. Jhuo, H.-J.; Yeh, P.-N.; Liao, S.-H.; Li, Y.-L.; Cheng, Y.-S.; Chen, S.-A., Review on the Recent Progress in Low Band Gap Conjugated Polymers for Bulk Hetero-junction Polymer Solar Cells. J. Chin. Chem. Soc. 2014, 61, 115-126.

13. Wienk, M. M.; Kroon, J. M.; Verhees, W. J. H.; Knol, J.; Hummelen, J. C.; van Hal, P. A.; Janssen, R. A. J., Efficient Methano[70]fullerene/MDMO-PPV Bulk Heterojunction Photovoltaic Cells. Angew. Chem., Int. Ed. 2003, 42, 3371-3375. 
14. Lin, Y.; Li, Y.; Zhan, X., Small molecule semiconductors for high-efficiency organic photovoltaics. Chem. Soc. Rev. 2012, 41, 4245-4272.

15. Anthony, J. E., Small-Molecule, Nonfullerene Acceptors for Polymer Bulk Heterojunction Organic Photovoltaics. Chem. Mater. 2010, 23, 583-590.

16. Chochos, C. L.; Tagmatarchis, N.; Gregoriou, V. G., Rational design on n-type organic materials for high performance organic photovoltaics. RSC Adv. 2013, 3, 7160-7181.

17. Sonar, P.; Fong Lim, J. P.; Chan, K. L., Organic non-fullerene acceptors for organic photovoltaics. Energy Environ. Sci. 2011, 4, 1558-1574.

18. Guo, X.; Kim, F. S.; Seger, M. J.; Jenekhe, S. A.; Watson, M. D., Naphthalene DiimideBased Polymer Semiconductors: Synthesis, Structure-Property Correlations, and n-Channel and Ambipolar Field-Effect Transistors. Chem. Mater. 2012, 24, 1434-1442.

19. Zhang, X.; Lu, Z.; Ye, L.; Zhan, C.; Hou, J.; Zhang, S.; Jiang, B.; Zhao, Y.; Huang, J.; Zhang, S.; Liu, Y.; Shi, Q.; Liu, Y.; Yao, J., A Potential Perylene Diimide Dimer-Based Acceptor Material for Highly Efficient Solution-Processed Non-Fullerene Organic Solar Cells with $4.03 \%$ Efficiency. Adv. Mater. 2013, 25, 5791-5797.

20. Zang, Y.; Li, C.-Z.; Chueh, C.-C.; Williams, S. T.; Jiang, W.; Wang, Z.-H.; Yu, J.-S.; Jen, A. K. Y., Integrated Molecular, Interfacial, and Device Engineering towards HighPerformance Non-Fullerene Based Organic Solar Cells. Adv. Mater. 2014, 26, 5708-5714.

21. Lin, Y.; Wang, J.; Zhang, Z.-G.; Bai, H.; Li, Y.; Zhu, D.; Zhan, X., An Electron Acceptor Challenging Fullerenes for Efficient Polymer Solar Cells. Adv. Mater. 2015, 27, 1170-1174.

22. Liu, Y.; Mu, C.; Jiang, K.; Zhao, J.; Li, Y.; Zhang, L.; Li, Z.; Lai, J. Y. L.; Hu, H.; Ma, T.; Hu, R.; Yu, D.; Huang, X.; Tang, B. Z.; Yan, H., A Tetraphenylethylene Core-Based 3D Structure Small Molecular Acceptor Enabling Efficient Non-Fullerene Organic Solar Cells. Adv. Mater. 2015, 27, 1015-1020.

23. Holliday, S.; Ashraf, R. S.; Nielsen, C. B.; Kirkus, M.; Röhr, J. A.; Tan, C.-H.; ColladoFregoso, E.; Knall, A.-C.; Durrant, J. R.; Nelson, J.; McCulloch, I., A Rhodanine Flanked Nonfullerene Acceptor for Solution-Processed Organic Photovoltaics. J. Am. Chem. Soc. 2015, 137, 898-904.

24. Mu, C.; Liu, P.; Ma, W.; Jiang, K.; Zhao, J.; Zhang, K.; Chen, Z.; Wei, Z.; Yi, Y.; Wang, J.; Yang, S.; Huang, F.; Facchetti, A.; Ade, H.; Yan, H., High-Efficiency All-Polymer Solar Cells Based on a Pair of Crystalline Low-Bandgap Polymers. Adv. Mater. 2014, 26, 7224-7230.

25. Zhou, Y.; Kurosawa, T.; Ma, W.; Guo, Y.; Fang, L.; Vandewal, K.; Diao, Y.; Wang, C.; Yan, Q.; Reinspach, J.; Mei, J.; Appleton, A. L.; Koleilat, G. I.; Gao, Y.; Mannsfeld, S. C. B.; Salleo, A.; Ade, H.; Zhao, D.; Bao, Z., High Performance All-Polymer Solar Cell via Polymer Side-Chain Engineering. Adv. Mater. 2014, 26, 3767-3772.

26. Earmme, T.; Hwang, Y.-J.; Subramaniyan, S.; Jenekhe, S. A., All-Polymer Bulk Heterojuction Solar Cells with $4.8 \%$ Efficiency Achieved by Solution Processing from a CoSolvent. Adv. Mater. 2014, 26, 6080-6085.

27. Bloking, J. T.; Han, X.; Higgs, A. T.; Kastrop, J. P.; Pandey, L.; Norton, J. E.; Risko, C.; Chen, C. E.; Brédas, J.-L.; McGehee, M. D.; Sellinger, A., Solution-Processed Organic Solar Cells with Power Conversion Efficiencies of $2.5 \%$ using Benzothiadiazole/Imide-Based Acceptors. Chem. Mater. 2011, 23, 5484-5490.

28. Hwang, Y.-J.; Courtright, B. A. E.; Ferreira, A. S.; Tolbert, S. H.; Jenekhe, S. A., 7.7\% Efficient All-Polymer Solar Cells. Adv. Mater. 2015, 27, 4578-4584. 
29. Ye, L.; Jiao, X.; Zhou, M.; Zhang, S.; Yao, H.; Zhao, W.; Xia, A.; Ade, H.; Hou, J., Manipulating Aggregation and Molecular Orientation in All-Polymer Photovoltaic Cells. Adv. Mater. 2015, 27, 6046-6054.

30. Chou, K. W.; Yan, B.; Li, R.; Li, E. Q.; Zhao, K.; Anjum, D. H.; Alvarez, S.; Gassaway, R.; Biocca, A.; Thoroddsen, S. T.; Hexemer, A.; Amassian, A., Spin-Cast Bulk Heterojunction Solar Cells: A Dynamical Investigation. Adv. Mater. 2013, 25, 1923-1929.

31. Bartelt, J. A.; Beiley, Z. M.; Hoke, E. T.; Mateker, W. R.; Douglas, J. D.; Collins, B. A.; Tumbleston, J. R.; Graham, K. R.; Amassian, A.; Ade, H.; Fréchet, J. M. J.; Toney, M. F.; McGehee, M. D., The Importance of Fullerene Percolation in the Mixed Regions of PolymerFullerene Bulk Heterojunction Solar Cells. Adv. Energy Mater. 2013, 3, 364-374.

32. Yang, X.; Loos, J.; Veenstra, S. C.; Verhees, W. J. H.; Wienk, M. M.; Kroon, J. M.; Michels, M. A. J.; Janssen, R. A. J., Nanoscale Morphology of High-Performance Polymer Solar Cells. Nano Lett. 2005, 5, 579-583.

33. Campoy-Quiles, M.; Ferenczi, T.; Agostinelli, T.; Etchegoin, P. G.; Kim, Y.; Anthopoulos, T. D.; Stavrinou, P. N.; Bradley, D. D. C.; Nelson, J., Morphology evolution via self-organization and lateral and vertical diffusion in polymer:fullerene solar cell blends. Nat. Mater. 2008, 7, 158-164.

34. Shu, Y.; Lim, Y.-F.; Li, Z.; Purushothaman, B.; Hallani, R.; Kim, J. E.; Parkin, S. R.; Malliaras, G. G.; Anthony, J. E., A survey of electron-deficient pentacenes as acceptors in polymer bulk heterojunction solar cells. Chem. Sci. 2011, 2, 363-368.

35. Huang, D. M.; Faller, R.; Do, K.; Moulé, A. J., Coarse-Grained Computer Simulations of Polymer/Fullerene Bulk Heterojunctions for Organic Photovoltaic Applications. J. Chem. Theory Comput. 2009, 6, 526-537.

36. Lee, C.-K.; Pao, C.-W., Solubility of [6,6]-Phenyl-C61-butyric Acid Methyl Ester and Optimal Blending Ratio of Bulk Heterojunction Polymer Solar Cells. J. Phys. Chem. C 2012, $116,12455-12461$.

37. Lee, C.-K.; Pao, C.-W.; Chu, C.-W., Multiscale molecular simulations of the nanoscale morphologies of P3HT:PCBM blends for bulk heterojunction organic photovoltaic cells. Energy Environ. Sci. 2011, 4, 4124-4132.

38. Jankowski, E.; Marsh, H. S.; Jayaraman, A., Computationally Linking Molecular Features of Conjugated Polymers and Fullerene Derivatives to Bulk Heterojunction Morphology. Macromolecules 2013, 46, 5775-5785.

39. Jorgensen, W. L.; Maxwell, D. S.; Tirado-Rives, J., Development and Testing of the OPLS All-Atom Force Field on Conformational Energetics and Properties of Organic Liquids. $J$. Am. Chem. Soc. 1996, 118, 11225-11236.

40. Darling, S. B.; Sternberg, M., Importance of Side Chains and Backbone Length in Defect Modeling of Poly(3-alkylthiophenes). J. Phys. Chem. B 2009, 113, 6215-6218.

41. Schwarz, K. N.; Kee, T. W.; Huang, D. M., Coarse-grained simulations of the solutionphase self-assembly of poly(3-hexylthiophene) nanostructures. Nanoscale 2013, 5, 2017-2027.

42. Sigma-Aldrich Catalog. www.sigmaaldrich.com.

43. Hoover, W. G., Canonical dynamics: Equilibrium phase-space distributions. Phys. Rev. A 1985, 31, 1695-1697.

44. Hoover, W. G., Constant-pressure equations of motion. Phys. Rev. A 1986, 34, 24992500 . 
45. Ryckaert, J.-P.; Ciccotti, G.; Berendsen, H. J. C., Numerical integration of the cartesian equations of motion of a system with constraints: molecular dynamics of n-alkanes. J. Comput. Phys. 1977, 23, 327-341.

46. Hockney, R. W.; Eastwood, J. W., Computer Simulation Using Particles. Institute of Physics Publishing: Bristol, 1988.

47. Plimpton, S., Fast Parallel Algorithms for Short-Range Molecular Dynamics. J. Comput. Phys. 1995, 117, 1-19.

48. Sweetnam, S.; Graham, K. R.; Ngongang Ndjawa, G. O.; Heumüller, T.; Bartelt, J. A.; Burke, T. M.; Li, W.; You, W.; Amassian, A.; McGehee, M. D., Characterization of the Polymer Energy Landscape in Polymer:Fullerene Bulk Heterojunctions with Pure and Mixed Phases. $J$. Am. Chem. Soc. 2014, 136, 14078-14088.

49. Graham, K. R.; Erwin, P.; Nordlund, D.; Vandewal, K.; Li, R.; Ngongang Ndjawa, G. O.; Hoke, E. T.; Salleo, A.; Thompson, M. E.; McGehee, M. D.; Amassian, A., Re-evaluating the Role of Sterics and Electronic Coupling in Determining the Open-Circuit Voltage of Organic Solar Cells. Adv. Mater. 2013, 25, 6076-6082.

50. Burke, T. M.; McGehee, M. D., How High Local Charge Carrier Mobility and an Energy Cascade in a Three-Phase Bulk Heterojunction Enable $>90 \%$ Quantum Efficiency. Adv. Mater. 2014, 26, 1923-1928.

51. Huang, D. M., Computational Study of P3HT/C60-Fullerene Miscibility. Aust. J. Chem. 2014, 67, 585-591.

52. Vandewal, K.; Widmer, J.; Heumueller, T.; Brabec, C. J.; McGehee, M. D.; Leo, K.; Riede, M.; Salleo, A., Increased Open-Circuit Voltage of Organic Solar Cells by Reduced Donor-Acceptor Interface Area. Adv. Mater. 2014, 26, 3839-3843.

53. Chirvase, D.; Parisi, J.; Hummelen, J. C.; Dyakonov, V., Influence of nanomorphology on the photovoltaic action of polymer-fullerene composites. Nanotechnology 2004, 15, 1317.

54. Collins, B. A.; Gann, E.; Guignard, L.; He, X.; McNeill, C. R.; Ade, H., Molecular Miscibility of Polymer-Fullerene Blends. J. Phys. Chem. Lett. 2010, 1, 3160-3166.

55. Collins, B. A.; Tumbleston, J. R.; Ade, H., Miscibility, Crystallinity, and Phase Development in P3HT/PCBM Solar Cells: Toward an Enlightened Understanding of Device Morphology and Stability. J. Phys. Chem. Lett. 2011, 2, 3135-3145.

56. Vettorel, T.; Meyer, H., Coarse Graining of Short Polythylene Chains for Studying Polymer Crystallization. J. Chem. Theory Comput. 2006, 2, 616-629.

57. Noriega, R.; Rivnay, J.; Vandewal, K.; Koch, F. P. V.; Stingelin, N.; Smith, P.; Toney, M. F.; Salleo, A., A general relationship between disorder, aggregation and charge transport in conjugated polymers. Nat. Mater. 2013, 12, 1038-1044. 


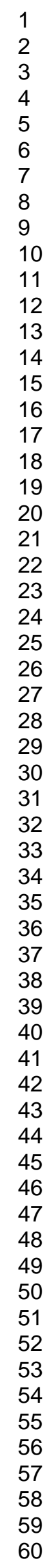




\section{TOC Figure:}
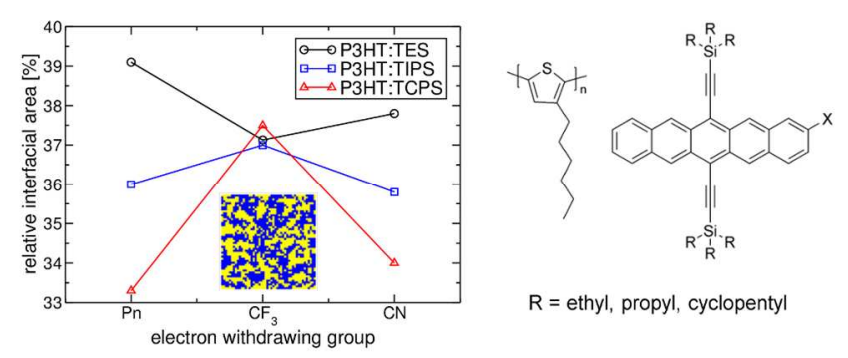